\section{P23 \\ FLOODING AND WEATHER-DAMAGED HOMES: AN ANALYSIS USING ENGLAND'S MENTAL HEALTH SURVEY}

${ }^{1} \mathrm{~S}$ McManus ${ }^{*},{ }^{2} \mathrm{H}$ Graham, ${ }^{3} \mathrm{P}$ White, ${ }^{4} \mathrm{~J}$ Cotton. ${ }^{1}$ Health Sciences, National Centre for Social Research, London, UK; ${ }^{2}$ University of York, York, UK; ${ }^{3}$ Department of Environment and Geography, University of York, York, UK; ${ }^{4}$ Environment Agency, Leeds, UK

\subsection{6/jech-2020-SSMabstracts.119}

Background Climate change is increasing population exposure to weather-related hazards, such as extreme precipitation, storms, and flooding. There's growing concern that such exposure affects people's mental health. However, little evidence exists based on probability samples or using robust assessment of mental disorders.

Methods We analysed the Adult Psychiatric Morbidity Survey, a representative study of adults in England $(n=7525)$. The most recent in the series asked about damage to the home (wind, rain, snow, flood) in the six months prior to interview. We investigated a) the social profile of those who experienced storm- and flood-damage, and b) whether experience of recent damage was independently associated with common mental disorder (CMD) after adjustment for other factors.

Results One person in twenty reported living in a storm or flood-damaged home in the previous six months $(n=354)$. Social advantage (home ownership, higher household income) increased the odds of exposure. People whose homes had been damaged were more likely to have CMD (23.1\%, 95\% CI 18.5-28.4) than the rest of the population $(16.7 \%, 95 \%$ $\mathrm{CI}: 15.7-17.8, \mathrm{p}=0.005)$. The strength of this association was similar to that of living in the most disadvantage Index of Multiple Deprivation quintile. Exposure was associated with CMD even when the damage had not forced them to leave the property. In adjusted regression analyses, recent exposure to living a storm or flood damaged home increased the odds of CMD by $50 \%$ (adjusted OR $1.5,95 \%$ CI 1.08; 2.07, $\mathrm{p}=0.014)$.

Conclusion Even relatively slight storm and flood damage to people's homes is linked with higher rates of CMD. With climate change increasing the frequency and severity of storms and flooding, improving community resilience and disaster preparedness must be a priority. Understanding the mental health context of exposed populations is key to building this capacity.

\section{P24 \\ HOUSEHOLD AIR POLLUTION AND ANAEMIA IN WOMEN AND CHILDREN: A CROSS-SECTIONAL STUDY OF SIX SUB-SAHARAN AFRICA COUNTRIES}

E Phillip*, P Corcoran. School of Public Health, University College Cork, Cork, Ireland

\subsection{6/jech-2020-SSMabstracts. 120}

Background Globally, anaemia affects 0.5 billion reproductiveaged women and $42 \%$ of children under 5 -year-olds. Over three billion people use polluting fuel daily mostly in low and low-middle-income countries. Most of these countries have severe public health significance of anaemia. Previous studies examined grouped effect of household fuel and health outcomes. We examined the associated risk of anaemia in women and children in Sub-Saharan Africa from exposure to individual cooking fuel types.

Methods This study explored the most recent data from Demographic and Health Survey (2013-2018) program. It involves nationally representative samples of women, children and household data in Ghana, Malawi, Rwanda, Tanzania, Uganda, and Zimbabwe. Anaemia, the outcome variable in women of reproductive age (15-49 years) and children aged 6-59 months, was ascertained from haemoglobin testing results carried out by trained field staff. The exposure variable was fuel used primarily in the households asked from the questionnaire. Descriptive analysis and multivariate Poisson regression analyses were done to estimate the risk of anaemia in both sample populations from exposure to cooking fuels after adjusting for several social determinants of health variables.

Results Overall, 93\% of the total sampled population $(55,742)$ were exposed to polluting cooking fuel, with $35 \%$ and $54 \%$ anaemia prevalence in women and children, respectively. In women, higher risk of anaemia was associated with exposure to liquid-petroleum-gas, adjusted risk ratios $1.29[95 \% \mathrm{CI}$ 1.03-1.63], $\mathrm{p}=0.03$; charcoal 1.23 [1.05-1.44], $\mathrm{p}=0.01$. Higher risk in children includes LPG 1.19 [1.01-1.41) $\mathrm{p}=0.04$; coal/lignite $1.21[1.11-1.36] \mathrm{p}<0.00$; and natural-gas $1.73[1.18-2.53], p=0.01$. The highest risk of anaemia $(89 \%)$ was found in children aged 6-11 months.

Conclusion The study adds to the body of evidence of the risk to health of women and children from the specific fuel used for cooking. It is urgent for policymakers to prioritise funding for clean, affordable, equitable fuel in these low-middle-income countries and for implementation research to establish the best suited for each community based on resources available to them. The increase in global migration calls for healthcare professionals to enhance socio-demographic history taking to include detailed information about fuel use for the accurate diagnosis of anaemia.

\section{P25 PILOTING A GROUP-BASED MODELLING APPROACH TO EXPLORE LOCAL FOOD SYSTEMS WITH AN AGENT-BASED MODEL}

${ }^{1} \mathrm{E}$ Schwaller*, ${ }^{1} \mathrm{C}$ Kypridemos, ${ }^{2} \mathrm{M}$ Green, ${ }^{1} \mathrm{~S}$ Capewell, ${ }^{1} \mathrm{M}$ O'Flaherty. 'Department of Public Health and Policy, University of Liverpool, Liverpool, UK; ${ }^{2}$ Department of Geography and Planning, University of Liverpool, Liverpool, UK

\subsection{6/jech-2020-SSMabstracts.121}

Background Daily dietary choices can be influenced by a host of behavioural factors (e.g., personal preferences, mental health state), as well as the social and policy environment (affordability, acceptability, and availability). Prioritising food environment policy changes to address dietary quality is thus challenging, and not well suited to some traditional research approaches.

Complex systems science is increasingly gaining ground in public health research and can be leveraged to better understand the determinants of poor dietary intake. Key methods include conceptual model building and computational modelling techniques. A co-production process called group model building (GMB) aims to bridge local issues and policy options. Traditionally, GMB has been used alongside system dynamics but not in agent-based modelling (ABM).

We, therefore, pilot a group modelling approach to inform development of a conceptual model of the local food environment in the Liverpool City Region to inform an ABM.

Methods We adapted and piloted a series of GMB stakeholder engagement activities (called scripts) for use in the ABM conceptual model with academics and partners from the local authority. We also developed a series of use-cases - policy 
scenarios to be modelled by the ABM - to facilitate discussion and solicit feedback on the conceptual model specifications. The feedback from the sessions were collated and reviewed and adjustments were made to both the conceptual model and the use-cases.

Results Upon reaching a shared understanding of the model concept, participants identified gaps in the conceptual model and developed new use case scenarios to be adjusted for future iterations. A number of feedback loops in the model were also highlighted for further consideration (e.g., travel choice, food price elasticity). Data collected from the session also supplied valuable input into development of suitable visual boundary objects that will be used to facilitate additional group modelling exercises and conversations with stakeholders. Additional meetings with stakeholders will further refine the conceptual model and provide ground truthing to the computational model.

Conclusion This iterative process facilitated the understanding of the complex systems underpinning local food environments and allows for ground truthing and future validation of the ABM. Co-development of model use cases facilitated a shared understanding of the purposes of the model and will help to maximise its usefulness for stakeholders.

\section{P26 HOW DOES CHANGING THE PLACEMENT OF FOOD PRODUCTS IN SUPERMARKETS INFLUENCE CUSTOMERS' PURCHASING AND STORE SALES?}

${ }^{1} \mathrm{~S}$ Crozier*, ${ }^{1,2} \mathrm{~J}$ Baird, ${ }^{1,2} \mathrm{C}$ Cooper, ${ }^{1,2} \mathrm{C}$ Vogel. ${ }^{1} \mathrm{MRC}$ Lifecourse Epidemiology Unit, University of Southampton, Southampton, UK; ${ }^{2}$ NIHR Southampton Biomedical Research Centre, University Hospital Southampton NHS Foundation Trust, Southampton, UK

\subsection{6/jech-2020-SSMabstracts. 122}

Background Supermarkets are a major source of food for families, yet greater understanding of how product placement strategies influence the healthfulness of food choice is needed. We assessed the effect of improving the availability and positioning of fruit and vegetables in supermarkets, and removing confectionery from checkouts, on household-level purchases and store-level sales.

Methods This study was a natural experiment with a prospective matched cluster design set in a discount supermarket chain in England. The intervention had two components: new fresh fruit and vegetable sections at store entrances (replacing smaller displays at the back), and removal of confectionery from checkouts (replacing with healthier items, such as sugarfree gum, water and non-food items) and end-of-aisle opposite checkouts. Women customers aged 18 to 45 years, with a store loyalty card, who regularly shopped at three intervention and three matched control stores in England were recruited. Data from purchases using loyalty cards and for store sales were collected for the three months before and six months after refurbishment. Individual purchasing data were analysed using a difference-in-difference method, while store sales data were analysed using controlled interrupted time series by store pair, with differences synthesised using random-effects metaanalysis.

Results A total of 107 women provided household-level purchasing data. The proportion purchasing fresh fruit and vegetables per week rose in intervention stores at three months $(0.2 \%)$ compared to a drop in control stores $(-3.0 \%)$ $(\mathrm{P}=0.22)$, and at six months $(1.7 \%$ vs $-3.5 \%, \mathrm{P}=0.05)$. The proportion purchasing healthier checkout items rose more in intervention stores compared to a drop in control stores at both three $(1.0 \%$ vs $-1.8 \%, \mathrm{P}=0.04)$ and six $(0.6 \%$ vs $-1.6 \%$, $\mathrm{P}=0.13)$ months. There were no differences in the purchases of frozen fruit and vegetables or confectionery. Increases in store-level sales of fresh fruit and vegetables were greater in intervention stores than predicted at three months (1.71SDs (95\% CI 0.45, 2.96), $\mathrm{P}=0.01$ ) and six months (2.42SDs $(0.22$, 4.62), $\mathrm{P}=0.03)$. Decreases in sales of confectionery were greater in intervention stores than predicted at three months (-1.05SDs $(-1.98,-0.12), \mathrm{P}=0.03)$ and six months $(-1.37$ SDs ($2.95,0.22), P=0.09)$. Sales of frozen fruit and vegetables and healthier checkout items showed no differences.

Conclusion This study provides some evidence to suggest that healthier product placement in supermarkets improves the healthfulness of both household-level purchasing and storelevel sales. Improving fruit and vegetable placement should be considered by government alongside current plans to limit prominent placement of unhealthy foods.

\section{P27 DIET - IS THERE A NEW DIGITAL DIVIDE? SOCIAL INEQUALITIES IN USE OF DIGITAL FOOD DELIVERY SERVICES AND ASSOCIATIONS WITH BMI}

${ }^{1} \mathrm{~S}$ Cummins ${ }^{*},{ }^{1} \mathrm{~N}$ Berger, ${ }^{1} \mathrm{~V}$ Er, ${ }^{2} \mathrm{C}$ Thompson, ${ }^{1} \mathrm{C}$ Law, ${ }^{1} \mathrm{~L}$ Cornelsen. ${ }^{1}$ Population Health Innovation Lab, London School of Hygiene and Tropical Medicine, London, UK; ${ }^{2}$ School of Health and Social Work, University of Hertfordshire, Hatfield, UK

10.1136/jech-2020-SSMabstracts. 123

Background Food retailing is undergoing a fundamental transformation. Digital on-demand technology is dramatically reshaping food distribution and delivery, making food and prepared meals more accessible and convenient. The impact of this disruption on food purchasing and consumption behaviour and dietary inequalities is unknown. This study aims to explore whether there is a social gradient in use of digital food delivery services for both take-away food and grocery purchasing, and whether use of these services is associated with BMI.

Methods We used data from UK Kantar Fast Moving Consumer Goods (FMCG) panel, a nationally representative panel study of all take-home household food and beverage purchasing. We used data from London and the North West of England $(n=1559)$ from February 2019. Households reported usage of digital take-away food delivery services (past 7 days) through a bespoke online survey. We used logistic regression models to estimate the odds of delivery service usage by occupational grade $(\mathrm{AB}, \mathrm{C} 1, \mathrm{C} 2, \mathrm{DE})$ and income $(£ 0-20 \mathrm{~K}, £ 20+-$ $50 \mathrm{~K}, £ 50 \mathrm{~K}+$ ) and to estimate whether usage was associated with BMI category $(<25 ; 25-29 ;>30)$, derived from selfreported height and weight. Results were adjusted for potential socio-demographic confounders.

Results For take-away food purchasing, 13\% of survey respondents had used a digital delivery service in the past 7 days. In fully adjusted models, a dose-response pattern was observed with lower occupational grade associated with higher usage for both C2 (OR 1.66, 95\% CI 1.01,2.73) and DE (OR 1.92, 95\% CI 1.18,3.09) households, compared to AB. Similar patterns were observed for household income. Use was associated with BMI category 25-29 (OR 1.52, 95\% CI 1.10, $2.29)$ and $30+(\mathrm{OR} 1.8,95 \%$ CI 1.18, 2.72), compared to $<25$. For digital grocery purchasing, $15.6 \%$ of households had 